\title{
CYCLOCRYOTHERAPY FOR CHRONIC GLAUCOMA AFTER VITREORETINAL SURGERY
}

\author{
C. K. L. CHEE, M. P. SNEAD and J. D. SCOTT \\ Cambridge
}

\begin{abstract}
SUMMARY
The case records were reviewed of 27 patients with chronic glaucoma after vitreoretinal surgery who underwent 28 cyclocryotherapy procedures between March 1987 and March 1992. The average intraocular pressure after 3 months was between 11.0 and $13.3 \mathrm{mmHg}$ with an average fall of 24-26 mmHg. More than $85 \%$ had intraocular pressures of less than $21 \mathrm{mmHg}$ after 3 months; $\mathbf{2 8 \%}$ were hypotonic (IOP $<6 \mathrm{mmHg}$ ). Six months postoperatively, $68 \%$ maintained or had improved vision. The hypotonic eyes were found to have deterioration in vision more frequently than those with an intraocular pressure $>5 \mathrm{mmHg}(57 \%$ compared with $24 \%)$. The odds of a hypotonic eye losing vision were 4.27 times greater than for a non-hypotonic eye. Cyclocryotherapy was successful in relief of pain in all 4 eyes which were painful pre-operatively.
\end{abstract}

Chronic glaucoma after vitreoretinal surgery is a significant problem and occurs in 6-14\% of cases after silicone oil injection. ${ }^{1,2}$ Filtration surgery with or without a Molteno implant resulted in a delayed expulsive choroidal haemorrhage in $10 \%$ of cases, often resulting in loss of the eye. As a consequence, cyclocryotherapy, performed in a standardised fashion, has gradually become the treatment of choice for uncontrolled glaucoma in patients who have undergone vitreoretinal procedures in this centre over the past 5 years. This study was performed to assess the results and complications of cyclocryotherapy after vitreoretinal surgery.

\section{PATIENTS AND METHODS}

A retrospective review was performed from the case records of 33 patients who had undergone 34 cyclocryotherapy procedures over 5 years from March 1987 to February 1992. Three patients were discharged soon after

From: Department of Ophthalmology, Addenbrooke's Hospital, Cambridge CB2 2QQ, UK.

Correspondence to: Dr Caroline K. L. Chee, Department of Ophthalmology, National University Hospital, 5 Lower Kent Ridge Road, Singapore 0511.

Eye (1994) 8, 414-418 C 1994 Royal College of Ophthalmologists surgery to the care of their ophthalmologist/optician from whom the long-term outcome was requested and provided in 2 cases. Two patients had no more than 3 months of follow-up and were excluded from the study. Three patients had no previous retinal surgery and were also excluded from the study. Twenty-seven patients who had undergone previous retinal surgery remained in the study. One of these patients had repeat cyclocryotherapy performed, bringing the total number of procedures to 28 . The length of follow-up after cyclocryotherapy was between 6 months and 5 years.

The patients were between 18 and 69 years old (average age 44.5 years). Nine were female, 18 were male. The original retinal problems are summarised in Table I. All were retinal detachments, of which 17 were associated with congenital eye problems, giant tears, proliferative diabetic retinopathy, trauma or retinal schisis. The original surgery had been performed 1-12 years (average 4.5 years) earlier and included vitrectomy with injection of intravitreal silicone oil in 26 patients and scleral buckling without vitrectomy in 1 patient. Either 1000 or $5000 \mathrm{cs}$ silicone oil was used. The total number of retinal operations undergone by each patient ranged from 1 to 5 (average 2.2). Silicone oil was removed in 7 (27\%) patients after 4-36 months (average 18 months). In another 4 (15\%) patients silicone oil was removed after 1-9 years, but had to be replaced after redetachment of the retina 2

Table I. Diagnosis of patients undergoing cyclocryotherapy

\begin{tabular}{lrc}
\hline Diagnosis & No. of patients \\
\hline Rhegmatogenous retinal detachment & 10 \\
Retinal detachment with congenital disorders & 7 \\
$\quad$ Stickler`s syndrome & 2 & \\
Congenital cataract & 1 & \\
Congenital glaucoma & 1 & \\
$\quad$ Bilateral coloboma & 1 & 4 \\
$\quad$ Klinefelter's syndrome & & 3 \\
Giant tear & 2 \\
Proliferative diabetic retinopathy & 1 \\
Trauma & -27 \\
Schisis detachment & \\
\end{tabular}


Table II. Pre-operative and post-operative vision

\begin{tabular}{lccccc}
\hline & $6 / 18-6 / 60$ & $1 / 60-5 / 60$ & $\mathrm{CF}$ & $\mathrm{HM}$ & $\mathrm{PL}$ \\
\hline Pre-operative & 6 & 5 & 7 & 8 & 2 \\
6 months post-operative & 4 & 7 & 5 & 9 & 3 \\
\hline
\end{tabular}

CF, counting fingers; HM, hand movements; PL, perception of light.

weeks to 9 years after removal of the oil. Silicone oil was not removed in $15(58 \%)$ patients. Twenty-two (79\%) patients were aphakic. Seven (26\%) patients had a history of glaucoma before silicone oil injection or before retinal surgery. All patients had chronic glaucoma with no pupil block at the time of surgery.

The pre-operative intraocular pressure ranged from 20 to $68 \mathrm{mmHg}$ (average $37.2 \mathrm{mmHg}$ ). The pre-operative vision was between $6 / 18$ and perception of light (Table II). The indication for surgery was sight preservation in 22 eyes, failed medical treatment in 26 eyes, intolerance to acetazolamide in 3 eyes and pain relief in 4 eyes. Preoperatively the patients had been on $1-4$ (average 2.6) pressure-lowering drugs which included beta blockers, pilocarpine, propine or adrenaline, phospholine iodine and acetazolamide (Table III).

Cyclocryotherapy was performed by four surgeons using a standard technique with the patient under general anaesthesia. The retinal probe of the Keeler-Amoils Cryo Unit ACU Mk 2 was placed $3-4 \mathrm{~mm}$ behind the limbus so that the edge of the iceball terminated at the corneoscleral junction. The cryopexy was applied until the iceball reached its maximum diameter, which took about 45 seconds. The first 3 patients were treated with $180^{\circ}$ cyclocryotherapy; in the other 25 procedures all $360^{\circ}$ of the ciliary body were treated. The number of applications of cryopexy ranged from 7 to 13 (average 11-12). Post-operatively, topical corticosteroids and cycloplegics were applied.

The intraocular pressure and visual acuity were recorded at 1, 3,6 and 12 months post-operatively. Visual acuity was recorded on a Snellen chart. Patients with vision poorer than $6 / 60$ were recorded as having $1-5 / 60$ vision, counting fingers, hand movements, perception of light or no perception of light. Visual improvement or deterioration was recorded on the basis of a change of 2 lines of Snellen acuity or a change from one of the previously mentioned categories to another. The presence of

Table III. Pre-operative medication of patients

\begin{tabular}{lc}
\hline Medication & No. of patients \\
\hline Beta blocker & 27 \\
Pilocarpine & 13 \\
Propine/adrenaline & 6 \\
Phospholine iodine & 6 \\
Acetazolamide & 22 \\
\hline No. of medications & No. of patients \\
\hline 1 & 2 \\
2 & 9 \\
4 & 13 \\
& 3 \\
\hline
\end{tabular}

Average no. of medications: 2.6. ocular pain, uveitis, cataract and ocular hypotony or phthisis bulbi were recorded. We defined ocular hypotony as an intraocular pressure of below $6 \mathrm{mmHg}$ and phthisis bulbi as a shrunken eye with no perception of light.

\section{RESULTS}

The post-operative intraocular pressures are summarised in Table IV. The average intraocular pressure 1 month post-operatively was $21.7 \mathrm{mmHg}$ (range $10-32 \mathrm{mmHg}$ ), an average fall of $15 \mathrm{mmHg}$. After 3 months the average intraocular pressure remained stable at from 11.0 to 13.3 $\mathrm{mmHg}$ (range $0-32 \mathrm{mmHg}$ ), with an average fall of 24-26 $\mathrm{mmHg}$. More than $85 \%$ of patients had intraocular pressures of less than $21 \mathrm{mmHg}$ after 3 months, and this was maintained after 1 year. This excludes 1 eye which required a Molteno implant for control of continued raised intraocular pressure $(36 \mathrm{mmHg}) 6$ weeks after cyclocryotherapy; this reduced the pressure to $14-20 \mathrm{mmHg}$. The pre- and post-operative intraocular pressures at the latest follow-up (between 6 months to 5 years) are summarised in Fig. 1.

In 6 eyes (21.4\%), cyclocryotherapy failed to bring the intraocular pressure below $21 \mathrm{mmHg}$. Four of these were treated with topical beta blockers and 2 underwent repeat cyclocryotherapy. Of the 4 eyes on topical beta blockers, 3 had intraocular pressures above $21 \mathrm{mmHg}$ despite medication and 1 of these underwent repeat cyclocryotherapy 3 years after the first procedure. One eye had a Molteno tube implanted 6 weeks after cyclocryotherapy for an intraocular pressure of $36 \mathrm{mmHg}$. The average number of cryopexy applications in the eyes with intraocular pressures greater than $21 \mathrm{mmHg}$ was $9-10$ as opposed to 11-12 in the patients who had pressures of less than 21 mmHg.

Between $22 \%$ and $28 \%$ of eyes were hypotonic with intraocular pressures of less than $6 \mathrm{mmHg}$ after 3 months to 1 year. In 2 of these 7 eyes the indication for surgery had been pain relief. The average number of cryopexy applications in the hypotonic eyes was 11-12 - no different from the average number of cryopexy applications in patients with pressures of $6 \mathrm{mmHg}$ or greater.

Table IV. Pre-operative and post-operative intraocular pressure (IOP)

\begin{tabular}{|c|c|c|c|c|c|}
\hline \multirow{2}{*}{$\begin{array}{l}\text { IOP } \\
(\mathrm{mmHg})\end{array}$} & \multirow{2}{*}{$\begin{array}{c}\text { Pre- } \\
\text { operative }\end{array}$} & \multicolumn{4}{|c|}{ Post-operative (months) } \\
\hline & & 3 & 6 & 12 & $18-24$ \\
\hline 0 & 0 & $1(4 \%)$ & $1(4 \%)$ & $1(5 \%)$ & $1(8 \%)$ \\
\hline $1-5$ & 0 & $5(19 \%)$ & $6(22 \%)$ & $5(23 \%)$ & $4(33 \%)$ \\
\hline $6-20$ & $2(7 \%)$ & $17(63 \%)$ & $17(63 \%)$ & $13(59 \%)$ & $6(50 \%)$ \\
\hline $21-30$ & $4(14 \%)$ & $4(15 \%)$ & $2(7 \%)$ & $2(9 \%)$ & $1(8 \%)$ \\
\hline $31-40$ & $15(54 \%)$ & 0 & $1 \quad(4 \%)$ & $1(5 \%)$ & 0 \\
\hline $41-50$ & $4(14 \%)$ & 0 & 0 & 0 & 0 \\
\hline$>51$ & $3(11 \%)$ & 0 & 0 & 0 & 0 \\
\hline Molteno $^{a}$ & - & 1 & 1 & 1 & 1 \\
\hline Total & 28 & 28 & 28 & 23 & 13 \\
\hline \multicolumn{6}{|l|}{ Summary } \\
\hline IOP range & $20-68$ & $0-28$ & $0-32$ & $0-32$ & $0-22$ \\
\hline Av. IOP & 37.2 & 11.0 & 11.0 & 13.3 & 13.2 \\
\hline Av. fall & -- & 26.2 & 26.2 & 23.9 & 24.0 \\
\hline IOP fall & - & $2-67$ & $2-67$ & $4-52$ & $0-50$ \\
\hline
\end{tabular}

"One eye underwent Molteno valve implantation for uncontrolled pressure of $36 \mathrm{mmHg} 6$ weeks after cyclocryotherapy. 


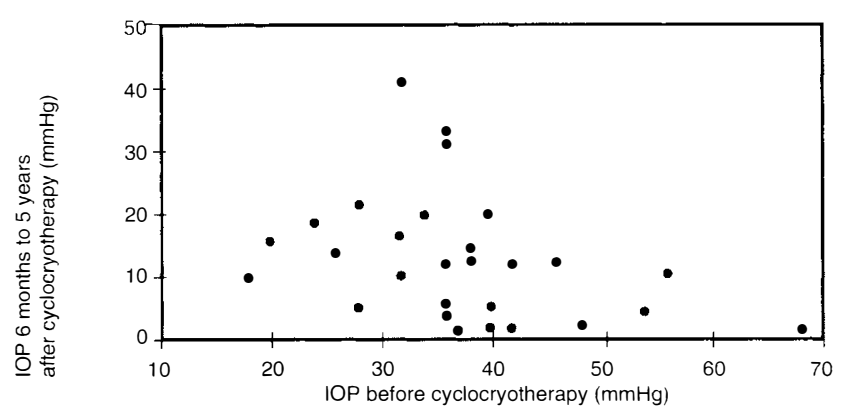

Fig. 1. Scattergram of pre-operative intraocular pressure against post-operative intraocular pressure at latest follow'up $(6$ months to 5 years). Four patients $(14 \%)$ had intraocular pressures of greater than $21 \mathrm{mmHg}$ after cyclocryotherapy despite medical treatment. One of these eyes underwent repeat cyclo(ryotherapy 3 years later.

Table $\mathrm{V}$ summarises the post-operative visual results. At 6 months after treatment 19 eyes $(68 \%)$ had retained the same vision or improved, and 9 (32\%) patients experienced a deterioration of vision. After 1 year. $36 \%$ of the eyes experienced a reduction in vision. Fig. 2 is a scattergram showing visual acuity before treatment and at the latest follow-up. Sixty-one per cent of eyes had retained or improved their vision and 39\% had deteriorated. Reduction in vision, where present, was no greater than from one category to the next, as can be seen by the parallel orientation of the points below the line or equivalence in Fig. 2 . The eyes which became hypotonic were associated with a deterioration of vision (57\%) more frequently than those with intraocular pressures $6 \mathrm{mmHg}$ or greater $(24 \%)$ (Table VI). The odds of a hypotonic eye losing vision were 4.27 times greater than for an eye which was not hypotonic.

Four patients complained of pain in the operated eye up to 2-4 weeks after surgery, but no pain was reported after 3 months. Successful relief of pain was achieved in the 4 eyes which underwent cyclocryotherapy for this indication.

Ocular inflammation in the form of lid swelling and chemosis, corneal oedema, anterior chamber flare, cells and hyphaema was a frequent finding in the early postoperalive period. After 3 months, 2 eyes of 22 were recorded as having flare and cells; after 6 months, only 1 eye was noted to have persistent flare and cells. Six patients were phakic, all of whom had varying amounts of lens opacities which could not be ascribed solely to the procedure. Four eyes underwent cataract extraction 5-15 months later. Eight eyes had band keratopathy or other corneal opacification, of which 2 subsequently underwent corneal grafts.

Table V. Change in vision after cyclocryotherapy

\begin{tabular}{lrrrrr}
\hline $\begin{array}{l}\text { Change } \\
\text { in vision }\end{array}$ & $\begin{array}{c}1 \\
\text { month } \\
(n=27)\end{array}$ & $\begin{array}{c}3 \\
\text { months } \\
(n=28)\end{array}$ & $\begin{array}{c}6 \\
\text { months } \\
(n=28)\end{array}$ & $\begin{array}{c}12 \\
\text { months } \\
(n=22)\end{array}$ & $\begin{array}{c}18-24 \\
\text { months } \\
(n=13)\end{array}$ \\
\hline Same & $17(63 \%)$ & $14(50 \%)$ & $16(57 \%)$ & $12(55 \%)$ & $6(46 \%)$ \\
Better & $4(15 \%)$ & $3(11 \%)$ & $3(11 \%)$ & $2(9 \%)$ & $2(15 \%)$ \\
Worse & $6(22 \%)$ & $11(39 \%)$ & $9(32 \%)$ & $8(36 \%)$ & $5(38 \%)$ \\
Same/ & $21(78 \%)$ & $17(61 \%)$ & $19(68 \%)$ & $14(64 \%)$ & $9(60 \%)$ \\
better & & & & & \\
\hline
\end{tabular}

\section{DISCUSSION}

Chronic glaucoma occurring after vitreoretinal surgery can arise from several mechanisms. Impairment of trabecular aqueous outflow is produced by ghost cells, uveitis, hyphaema, lens remnants after lensectomy, emulsified silicone oil and neovascular glaucoma. The initial trauma in traumatic retinal detachments, pre-existing glaucoma, pupil block, prolonged corticosteroid therapy and aphakia can also contribute to raised intraocular pressure. Schwartz syndrome, in which retinal detachment is associated with raised intraocular pressure resulting from photoreceptor outer segment fragments in the trabecular meshwork, may be an initial insult to the outflow apparatus.

The patients in this study had primary or secondary chronic open angle glaucoma and required surgery because of failed medical treatment, intolerance to acetazolamide or for control of ocular pain. Trabeculectomy has a high failure rate because of post-operative conjunctival scarring. Molteno valve implantation in this centre was associated with a $10 \%$ risk of developing late choroidal haemorrhage, which often resulted in loss of the eye.

Cyclocryotherapy, performed with the standardised technique described, was able to control the intraocular pressure in more than $85 \%$ of cases. Other investigators analysing results of cyclocryotherapy in the treatment of neovascular glaucoma, advanced glaucoma and aphakic glaucoma have reported between $29 \%$ and $77 \%$ success in reduction of intraocular pressure to below $21 \mathrm{mmHg}$. $^{3.12}$ Different techniques were utilised with regard to duration of cryopexy and extent of treatment, and retreatment was sometimes performed.

Pain relief was achieved in all 4 eyes treated for this purpose. Cyclocryotherapy is known to be an effective method of relieving pain in glaucomatous eyes with a success rate of $71.4-94 \%$. ${ }^{9.12}$ Relief of pain is usually achieved even if pressure control is not, ${ }^{3.9 .12}$ and this has been attributed by Grant ${ }^{1.3}$ to destruction of the corneal sensory nerves.

Thirty-six per cent of patients lost vision after 1 year (Table V). The degree of visual loss, when present, was confined to a fall from one category to the next, the categories being defined in Table II. The proportion of patients losing vision after cyclocryotherapy in other series varies. Bellows and Grant ${ }^{4}$ recorded only 2 of 26 patients (8\%) with aphakic open-angle glaucoma suffering significant visual loss; Benson and Nelson ${ }^{12}$ had a $30 \%$ rate of visual loss; Gross et al. ${ }^{11}$ reported $22 \%$ having severe visual loss. Krupin et al.'s" series on neovascular glaucoma reported 58\% losing light perception.

None of the eyes in our series became phthisical. The proportion of eyes becoming phthisical ranged from $6 \%$ when $180^{\circ}$ of the ciliary body was treated for advanced glaucoma by Caprioli et al., 5 to $34 \%$ after an average of 24.9 months follow-up in neovascular glaucoma by Krupin et al." The unacceptably high rate of visual loss and phthisis occurring in Krupin's series of neovascular glau- 


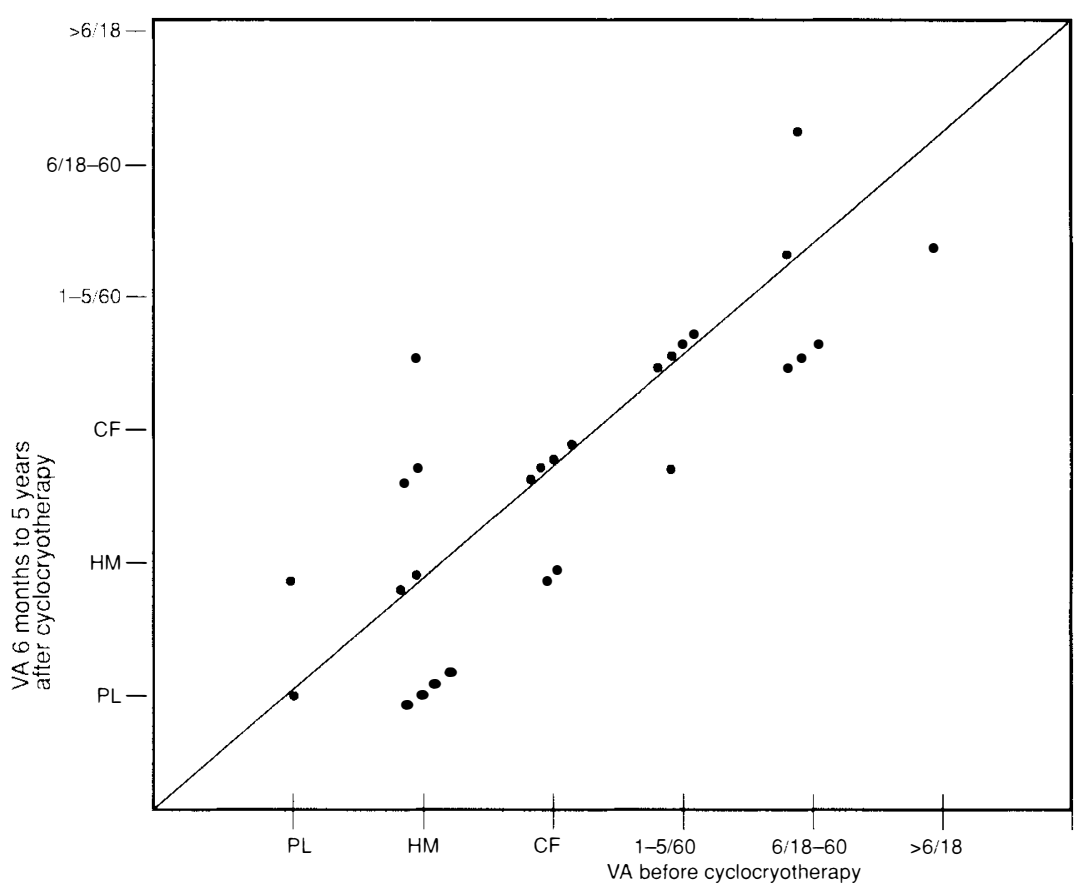

Fig. 2. Scattergram of visual acuity before and 6 months to 5 years after cyclocryotherapy: Sixty-one per cent of patients retained or improved their vision.

coma led Bellows and Grant ${ }^{4}$ to urge that cyclocryotherapy not be used in the treatment of neovascular glaucoma. Eleven eyes $(39 \%)$ in our study eventually became hypotonic. The odds of a hypotonic eye losing vision were 4.27 greater than for an eye which was not hypotonic. Feibel and Bigger ${ }^{3}$ found a similar incidence $(32 \%)$ of ocular hypotony; these eyes had vision of hand movements or less. The number of applications of cryopexy did not influence the risk of hypotony. Treating $180^{\circ}$ rather than $360^{\circ}$ of the ciliary body may result in a lower rate of hypotony, possibly with a consequent lower rate of visual loss; however, an increased failure to control raised intraocular pressure is also likely to occur.

After the early post-operative period, pain and uveitis were not found to be problems. Reported complications such as sympathetic ophthalmia, ${ }^{14}$ lens dislocation, ${ }^{15}$ subretinal fibrosis ${ }^{16}$ and anterior segment ischaemia ${ }^{9}$ did not occur in this small series of patients.

All the eyes in this study had complex vitreoretinal problems and poor prognoses from multiple pathology. Not many alternatives for the control of the raised intraocular pressure were available. Cycloablation can also be achieved with trans-scleral photocoagulation or ultrasound, which have the advantage of causing less postoperative inflammation. However, the continuous wave

Table VI. Visual outcome and ocular hypotony at 6 months

\begin{tabular}{lcll}
\hline & \multicolumn{3}{c}{ Vision } \\
\cline { 2 - 3 } $\begin{array}{l}\text { Intraocular } \\
\text { pressure }\end{array}$ & Same/better & Worse & Total \\
\hline $0-5 \mathrm{mmHg}$ & $3(43 \%)$ & $4(57 \%)$ & $7(10(1 \%)$ \\
$>5 \mathrm{mmHg}$ & $16(76 \%)$ & $5(24 \%)$ & $21(100 \%)$ \\
Total & 19 & 9 & 28 \\
\hline
\end{tabular}

Odds Ratio: Hypotonic eyes were 4.27 times more likely to have worse vision than eyes with intraocular pressure greater than $5 \mathrm{mmHg}$.
YAG or diode laser and/or ultrasound equipment required for these procedures are not yet widely available. Cryotherapy equipment is available in most centres, and cyclocryotherapy, performed in the standardised method described, resulted in $68 \%$ and $64 \%$ of eyes maintaining or experiencing an improvement in vision after 6 months and 1 year respectively. Coupled with the good control of intraocular pressure and a relatively low complication rate, this procedure has been found to be useful in situations which otherwise may have resulted in loss of the eye.

Key words: Chronic glaucoma, Cyclocryotherapy results, Silicone oil, Vitreoretinal surgery.

\section{REFERENCES}

1. Riedel KG, Gabel VP, Neubauer L, Kampik A, Lund OE. Intravitreal silicone oil injection: complications and treatment of 415 consecutive patients. Graefes Arch Clin Exp Ophthalmol 1990;228:19-23.

2. Lucke K, Bopp S, Laqua H. Long-term fate of eyes with and without silicone oil removal. Abstracts from the programme of Club Jules Gonin XVIII Meeting, September 1992:69.

3. Feibel RM, Bigger JF. Rubeosis iridis and neovascular glaucoma. Am J Ophthalmol 1972;74:862-7.

4. Bellows AR. Grant WM. Cyclocryotherapy in advanced inadequately controlled glaucoma. Am J Ophthalmol 1973; 75:679-84

5. Caprioli J, Strang SL, Spaeth GL, Proyzees EH. Cyclocryotherapy in the treatment of advanced glaucoma. Ophthalmology 1985:92:947-53.

6. Krupin T, Mitchell KB. Cyclocryotherapy in advanced inadequately controlled glaucoma. Am J Ophthalmol 1973; 75:679-84.

7. Boniuk M. Cryotherapy in neovascular glaucoma. Trans Am Acad Ophthalmol Otolaryngol 1974;78:337.

8. Bellows AR. Grant WM. Cyclocryotherapy in chronic open 
angle glaucoma in aphakic eyes. Am J Ophthalmol 1978;85: 615-21.

9. Krupin T, Mitchell KB, Becker B. Cyclocryotherapy in neovascular glaucoma. Am J Ophthalmol 1978;86:24-6.

10. Brindley G, Shields MB. Value and limitations of cyclocryotherapy. Graefes Arch Clin Exp Ophthalmol 1986;224: $545-8$.

11. Gross RL, Feldman RM, Spaeth GL, Steinmann WC, Spiegel D, Katzz LJ, et al. Surgical therapy of chronic glaucoma in aphakia and pseudophakia. Ophthalmology 1988; 95:1195-201.

12. Benson MT, Nelson ME. Cyclocryotherapy: a review of cases over a 10-year period. Br J Ophthalmol 1990;74: 103-5.
13. Grant WM. Management of neovascular glaucoma. In: Leopold $\mathrm{IH}$, editor. Symposium on ocular therapy, vol 7. St Louis: CV Mosby, 1974.

14. Sabates R. Choroiditis compatible with the histopathologic diagnosis of sympathetic ophthalmia following cyclocryotherapy of neovascular glaucoma. Ophthalmic Surg 1988;19:176-82.

15. Pearson AP, Baldwin LB, Smith TJ. Lens subluxation as a complication of cyclocryotherapy. Ophthalmic Surg 1989; 10:544-6.

16. Kao SF, Morgan CM, Bergstrom TJ. Subretinal fibrosis following cyclocryotherapy: case report. Arch Ophthalmol 1987; 105:1175-6. 